\title{
POPULATION STRUCTURE AND LINKAGE DISEQUILIBRIUM ANALYSES OF MODEL PLANT Brachypodium distachion THROUGH iPBS MARKERS
}

\author{
Pinar GUNER ${ }^{l}$, Duygu ATES ${ }^{l}$, Metin TUNA ${ }^{2}$, Muhammed Bahattin TANYOLAC ${ }^{l *}$ \\ ${ }^{I}$ Ege University, Department of Bioengineering, Molecular Genetic Laboratory, Izmir, TURKEY \\ ${ }^{2}$ Namik Kemal University, Faculty of Agriculture, Department of Field Crops, Tekirdag, TURKEY \\ *Corresponding author: bahattin.tanyolac@gmail.com
}

Received: 13.10 .2020

\begin{abstract}
In the current study, a total of 235 genotypes of Brachypodium distachyon $(B D)$ were studied and targeted to evaluate the genetic diversity, population structure and relative kinship of these genotypes using inter-primer binding site (iPBS) markers. Twenty-eight iPBS markers were used, and 184 clear and sharp polymorphic bands were produced. The polymorphism information content and diversity parameters indicated the existence of an appropriate amount of genetic diversity in the analysed genotypes. The results of the dendrogram with heat map and principal component analysis (PCoA) revealed that 235 BD genotypes were grouped into two separate clusters. The population structure was calculated using the STRUCTURE software, and two major sub-groups $(K=2)$ were established. A total of $95.1 \%$ of the relative kinship estimates being less than 0.4 for all genotypes. The findings of this study concluded that iPBS markers are highly polymorphic and are very efficient in the evaluation of the genetic diversity of $B$. distachyon.
\end{abstract}

Keywords: Brachypodium distachyon, genetic diversity, inter-primer binding site (iPBS), linkage disequilibrium, population structure.

\section{INTRODUCTION}

$B D$ has a very small genome size among cereals and consists of approximately $272 \mathrm{Mbp}$ with a $\mathrm{C}$ value of 0.36 $\mathrm{pg} /$ haploid genome and haploid chromosomes $(\mathrm{x}=5)$ with 6 unmapped scaffolds (Ozdemir et al., 2008). It is a wild plant with a combination of many features required by a desirable and traceable experimental model, such as having the smallest genome, a self-fertilizing plant, easy growth conditions, a short generation time (eight weeks), a short physical length (approximately $20 \mathrm{~cm}$ ), a life cycle of less than four months, and easy genetic transformation (Bevan et al., 2010). Although, Arabidopsis thaliana, a model for all flowering plants, has a small genome (135 Mbp), it is quite distant from the Poaceae family. On the other hand, Oryza sativa is used as a model for the genomes of all temperate crop species, including major grains, such as barley and wheat. Among these, $B D$ is a better model for the grass genome than $O$. sativa, possessing the smallest genome in the Poaceae family (Draper et al., 2001).

The natural habitat of $B D$ covers the Middle East and the Mediterranean (Syria, Lebanon and Israel), including Turkey (Wilson et al., 2019). It is mainly distributed in Turkey's Southeast Anatolia. To date, several genetic diversity studies have been carried out on Turkish $B D$ (Filiz et al., 2009; Vogel et al., 2009; Gordon et al., 2014; Tyler et al., 2016; Stritt et al., 2018). In these studies, the genotypes were mainly collected from inland Turkey, and the results indicated a great genetic variation among the Turkish genotypes. to the best of our knowledge, the genotypes collected mainly from coastal regions of Turkey have not been studied in detail.

Apart from a few rare species, most of the genome of the eukaryotic organism is composed of dispersed repeat sequences and large-scale DNA sequencing. These are mainly transposable elements (TEs) and they can cause various types of mutation (Kalendar et al., 2011). They can also trigger other genetic rearrangements which they recombine in the plant genome. These unique properties make them a significant source of spontaneous mutation (Pereira and Ryan, 2019). These mutations sometimes can be advantageous to the plants, and certain TEs have been related to plant adaptation to various abiotic and biotic stress conditions (Pereira and Ryan, 2019). In addition, these mutations are generally related with the origin of new phenotypic and genetic diversity of plants (SerratoCapuchina and Matute, 2018).

Molecular markers originating from retrotransposons are powerful resources for plant genomic and phylogenetic analyses, because a significant proportion of genomic variation is sourced from TEs (Roy et al., 2014). In 
particular, the iPBS marker system has some advantages in comparison with other retrotransposon-based marker systems, such as the sequence information not being necessary when designing the primer, requiring a low amount of DNA, and ease of utilisation. In previous studies, several genetic diversity studies have been conducted in various crops using this marker system (Gedik et al., 2017; Ali et al., 2019). However, to the best of our knowledge, the present study is the first report on the identification and molecular characterization of $B D$ genotypes using iPBS markers.

Due to their genomic properties, TEs are used in various ways as a molecular marker (Kalendar et al., 2010). In the transposon studies performed on $B$. distachyon, retrotransposons constitute $21.4 \%$ of the genome (Vogel et al., 2010). The iPBS approach has recently been used for isolation and visualisation of the polymorphism of retrotransposons since it does not require predetermined sequence information and has high reproducibility due to its binding temperature and primary length (Guo et al., 2014). Recognising the degree, quantity and pattern of genetic diversity studies to be carried out with $B D$ population is important for their future utilisation in breeding studies which is expected to lead to rapid developments in genomic information production in order to improve all temperate crops, especially cereals (Bevan et al., 2010). However, iPBS markers have not been previously identified in $B$. distachyon; therefore, the current research was undertaken using these markers to determine the genetic diversity and population structure of $B D$ genotypes collected from Turkey.

\section{MATERIALS AND METHODS}

Plant materials and DNA extraction

In the present study, 235 BD genotypes collected from 63 different locations (mainly coastal regions) of Turkey were analysed (Table 1 and Figure 1). Plants were grown in greenhouses in Ege University (Izmir, Turkey) and fresh young leaves from each single plant representing genotypes (four-six weeks old) were harvested from each seedling for DNA isolation.

In accordance with the procedure of DNA isolation defined by Doyle and Doyle (1987), genomic DNA from fresh young leaves of each sample were isolated with minor modifications. The DNA purity was controlled by $1 \%$ agarose gel electrophoresis, and the DNA concentration was measured by a Nanodrop spectrophotometer (ND1000, Thermo Fisher Scientific Inc., USA). All DNA samples were diluted to $5 \mathrm{ng} \mu \mathrm{L}^{-1}$ concentration and stored at $-20^{\circ} \mathrm{C}$ until the start of iPBS analyses.

\section{iPBS PCR amplification}

A total of 35 iPBS primers (Table 2) designed by Kalendar et al. (2010) were tested for display on six randomly selected genotypes of $B D$ to observe which primers generated polymorphic and clear bands. DNA amplification was performed following the protocol of Kalendar et al. (2010) with minor modifications.

\section{Data analyses}

Sharp and clear amplified bands were scored manually for the absence and presence of the bands as 0 and 1, respectively. Effective alleles number $(\mathrm{Ne})$, polymorphism information content (PIC), Nei's gene diversity (He), and Shannon's information index (I) were calculated for each marker by the use of R Studio statistical program. The PIC of the markers was identified based on the formula defined by Anderson et al. (1993):

$P I C=1-\sum_{i} P i^{2}$

where $P$ is the frequency of the presence of each band. Additionally, resolving power (Rp) was utilised to test the ability of iPBS primers to discriminate all individuals (Prevost and Wilkinson, 1999). The Rp analysis was performed based on the following formula:

$$
R p=\sum I b \quad \text { and } \quad I b=1-[2 *(0.5-P)]
$$

A cluster test was conducted to construct a dendrogram on the basis of Jaccard index using the unweighted pairgroup method with arithmetic averages (UPGMA). The neighbour-joining tree was build and principal coordinate analysis (PCoA) was performed using the R studio software (Pal et al., 1996).

\section{Analysis of population structure}

The software STRUCTURE (v.2.2) (Pritchard et al., 2000) was used to ascertain the structure of the population consisting of $235 \mathrm{BD}$ genotypes. The values of hypothetical subpopulations $(\mathrm{K})$ was calculated from 1 to 10 , estimating the associated allele frequencies $[100,000$ Monte Carlo Markov chain (MCMC) replicates and a burnin period of 100,000]. STRUCTURE HARVESTER (Earl and VonHoldt, 2012) was used to measure the subpopulation number-Delta K (Evanno et al., 2005), the expected heterozygosity, and the fixation index ( Fst) (Earl and VonHoldt, 2012). 
Table 1. List of 235 B. distachyon accessions genotypes used for molecular characterisation analyses

\begin{tabular}{|c|c|c|c|c|c|c|c|c|c|c|c|}
\hline $\begin{array}{l}\text { Geno } \\
\text { no }\end{array}$ & Location & $\begin{array}{l}\text { Geno } \\
\text { no }\end{array}$ & Location & $\begin{array}{l}\text { Geno } \\
\text { no }\end{array}$ & Location & $\begin{array}{l}\text { Geno } \\
\text { no }\end{array}$ & Location & $\begin{array}{l}\text { Geno } \\
\text { no }\end{array}$ & Location & $\begin{array}{l}\text { Geno } \\
\text { no }\end{array}$ & Location \\
\hline 1 & Kozluk (Batman) & 40 & Dursunbey-Harmancik & 79 & Biyikali, Tekirdag (2) & 118 & İnecik & 157 & Yenice & 196 & Polatli- Haymana \\
\hline 2 & 18 Mart Univ. Kampus & 41 & Mugla & 80 & Pada Koyu & 119 & İnecik & 158 & İnecik & 197 & Polatli- Haymana \\
\hline 3 & TUBITAK Gen Merkezi & 42 & Kozluk (Batman) & 81 & Balya Yenice II & 120 & 18 Mart Univ. & 159 & Baragi, Kesan & 198 & Polatli Haymana \\
\hline 4 & Burdur-Bucak-2 & 43 & Eskisehir & 82 & Avanos III Nevsehir & 121 & İnecik & 160 & Yenice & 199 & Kaymaz cikisi Eskisehir \\
\hline 5 & Canakkale Serceler Koyu & 44 & Dursunbey- Balikesir & 83 & Haskoy, Enez & 122 & Agva Sile yolu II & 161 & Yenice & 200 & Eskisehir \\
\hline 6 & Kayi Koyu, Tekirdag & 45 & Polatli Haymana & 84 & Sarkoy & 123 & Sehitlik II Canakkale & 162 & Cenekoy, Hayrabolu & 201 & Polatli Haymana \\
\hline 7 & Harmancik- Kutahya & 46 & Mugla & 85 & Harmancik- Kutahya & 124 & İnecik & 163 & TUBITAK Gen Merk. & 202 & Kaymaz cikisi Eskisehir \\
\hline 8 & Harmancik- Kutahya & 47 & Eskisehir & 86 & Agva Sile yolu II & 125 & Agva Sile yolu II & 164 & Balikesir Merkez & 203 & Burdur-Bucak-1 \\
\hline 9 & Cenekoy, Hayrabolu & 48 & Balli, Sarkoy & 87 & Biyikali, Tekirdag (3) & 126 & 18 Mart Univ. & 165 & Golcuk, Sarkoy & 204 & Dursunbey- Balikesir \\
\hline 10 & Balikesir merkez II & 49 & Dursunbey-Harmancik & 88 & Avanos III Nevsehir & 127 & Avanos-Nevsehir & 166 & Canakkale sehitlik & 205 & İskender, Edirne \\
\hline 11 & Danisment & 50 & Kutahya-Eskisehir & 89 & Sarkoy & 128 & 18 Mart Univ. & 167 & Avanos III Nevsehir & 206 & İskender, Edirne \\
\hline 12 & Olacak, Meric & 51 & Dursunbey- Balikesir & 90 & Buzagici, Hayrabolu & 129 & Avanos 4 Nevsehir & 168 & Nevsehir & 207 & İskender, Edirne \\
\hline 13 & Burdur-Bucak-1 & 52 & Kahta (Adiyaman) & 91 & Avanos III Nevsehir & 130 & İnecik & 169 & Canakkale Bursa yolu & 208 & Balli, Sarkoy \\
\hline 14 & Kozluk (Batman) & 53 & Biyikali, Tekirdag (2) & 92 & Avanos-Nevsehir & 131 & Sehitlik II Canakkale & 170 & Biyikali, Tekirdag (2) & 209 & Ilgardere-Gelibolu \\
\hline 15 & Olacak, Meric & 54 & Kutahya Tavsanli & 93 & Buzagici, Hayrabolu & 132 & Avanos 4 Nevsehir & 171 & Polatli Haymana & 210 & Kayi Koyu, Tekirdag \\
\hline 16 & Olacak, Meric & 55 & Gaziantep-1 & 94 & Cakmak, Edirne & 133 & Balikesir merkez II & 172 & Eskisehir & 211 & Cenekoy, Hayrabolu \\
\hline 17 & Olacak, Meric & 56 & Balikesir Merkez & 95 & Danisment & 134 & 18 Mart Univ. & 173 & Kaymaz Eskisehir & 212 & \\
\hline 18 & Begendik & 57 & Dursunbey- Balikesir & 96 & Biyikali, Tekirdag (2) & 135 & Balikesir merkez II & 174 & Kutahya & 213 & İnecik \\
\hline 19 & 18 Mart Univ. & 58 & Kozluk (Batman) & 97 & Kilickoy, Kesan & 136 & Inecik & 175 & Pada Koyu & 214 & Yenice \\
\hline 20 & Ahmetli, Sile & 59 & Balya Yenice II & 98 & Golcuk, Sarkoy & 137 & Pada Koyu & 176 & Kaymaz/Eskisehir & 215 & İskender, Edirne \\
\hline 21 & Burdur-Bucak-2 & 60 & Can - Yenice & 99 & İzzetiye & 138 & Danisment & 177 & Polatli Haymana & 216 & İnecik \\
\hline 22 & Uveyizli, Sile & 61 & Dursunbey-Harmancik & 100 & Dursunbey- Balikesir & 139 & İzzetiye & 178 & Kutahya Tavsanli & 217 & Cenekoy, Hayrabolu \\
\hline 23 & Uveyizli, Sile & 62 & Vize & 101 & Nevsehir & 140 & Nevsehir & 179 & Kutahya-Eskisehir & 218 & İskender, Edirne \\
\hline 24 & Balya Yenice II & 63 & Kilickoy, Kesan & 102 & Avanos 4 Nevsehir & 141 & Burdur-Bucak-1 & 180 & Kutahya & 219 & Yenice Balya \\
\hline 25 & Biyikali, Tekirdag (3) & 64 & Balya Yenice II & 103 & Burdur-Bucak-1 & 142 & Buzagici, Hayrabolu & 181 & Polatli- Haymana & 220 & Haskoy, Enez \\
\hline 26 & Canakkale Bursa Yolu & 65 & Sehitlik II Canakkale & 104 & Dursunbey-Harmancik & 143 & Biyikali, Tekirdag (3) & 182 & Pada Koyu & 221 & Disbudak \\
\hline 27 & Dursunbey-Harmancik & 66 & Vize & 105 & Canakkale-Serceler & 144 & Yenice & 183 & Polatli- Haymana & 222 & Baragi, Kesan \\
\hline 28 & Kozluk (Batman) & 67 & Sehitlik II Canakkale & 106 & İnecik & 145 & Uveyizli, Sile & 184 & Canakkale Bursa Yolu & 223 & Biyikali, Tekirdag \\
\hline 29 & Adiyaman & 68 & Vize & 107 & Balikesir merkez II & 146 & Disbudak & 185 & Kutahya-Eskisehir & 224 & Balli, Sarkoy \\
\hline 30 & Kozluk (Batman) & 69 & Buzagici, Hayrabolu & 108 & İnecik & 147 & Danisment & 186 & Polatli- Haymana & 225 & Yesilsirt Koyu, Muratli \\
\hline 31 & Sile & 70 & İnecik & 109 & Avanos-Nevsehir & 148 & Yesilsirt Koyu, Muratli & 187 & Balya & 226 & Dursunbey- Balikesir \\
\hline 32 & Haskoy, Enez & 71 & Ciftlik, Uzunkopru & 110 & Agva Sile yolu II & 149 & Agva Sile yolu II & 188 & Pada Koyu & 227 & Can - Yenice \\
\hline 33 & Kilickoy, Kesan & 72 & Ciftlik, Uzunkopru & 111 & Kutahya Tavsanli & 150 & TUBITAK gen merk. & 189 & Polatli- Haymana & 228 & Baragi, Kesan \\
\hline 34 & Gaziantep-1 & 73 & Cenekoy, Hayrabolu & 112 & Mugla & 151 & Burdur-Bucak-2 & 190 & Nevsehir & 229 & Yenice Balya \\
\hline 35 & Gaziantep-1 & 74 & Ilgardere-Gelibolu & 113 & Kutahya Tavsanli & 152 & Kayi-Tekirdag & 191 & Kutahya-Eskisehir & 230 & Avanos 4 Nevsehir \\
\hline 36 & Dursunbey- Balikesir & 75 & Haskoy, Enez & 114 & İnecik & 153 & Balli, Sarkoy & 192 & Eskisehir & 231 & Burdur-Bucak-1 \\
\hline 37 & Sehitlik II Canakkale & 76 & Vize & 115 & Kutahya Tavsanli & 154 & İzzetiye & 193 & Polatli- Haymana & 232 & Yenice Balya \\
\hline 38 & Sile & 77 & Ilgardere-Gelibolu & 116 & İnecik & 155 & Agva Sile yolu II & 194 & Polatli- Haymana & 233 & İzzetiye \\
\hline \multirow[t]{2}{*}{39} & Ahmetli, Sile & 78 & Cakmak, Edirne & 117 & Balya & 156 & Burdur-Bucak-2 & 195 & Polatli- Haymana & 234 & Seymen, Corlu \\
\hline & & & & & & & & & & 235 & Buzagici, Hayrabolu \\
\hline
\end{tabular}




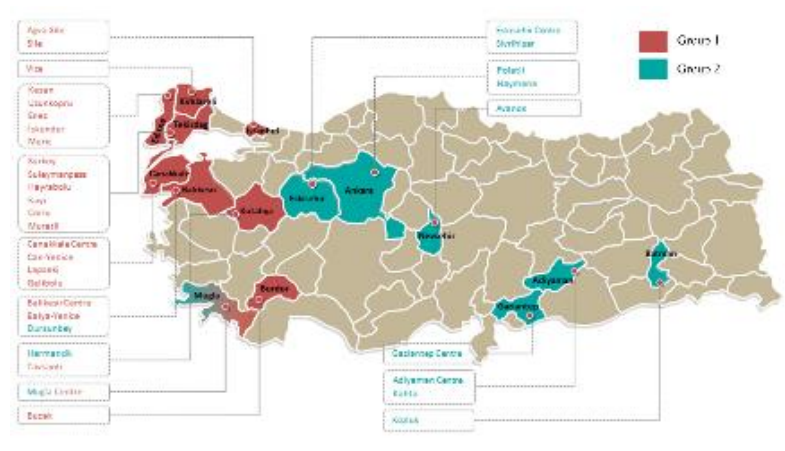

Figure 1. Geographical locations where 235 Brachypodium distachion genotypes were collected in Turkey

\section{RESULTS}

\section{Analyses of iPBS markers}

Thirty-five iPBS primers were evaluated with 28 indicating a clear, sharp and polymorphic bands profile (Table 2). Therefore, analyses were continued with these 28 primers, which produced 184 polymorphic bands with the proportion of $86 \%$ (Table 3 ). The average band number and polymorphic band number per primer were 8 and 7 , respectively. While the highest polymorphic band was detected as 13 (iPBS 2401), the lowest polymorphic band was found as 2 (iPBS 2273 and 2402). The primers having a polymorphic band ratio of $100 \%$ were iPBS 2085, 2255, 2257, 2273, 2298, 2389, 2393, 2399 and 2401 (Table 3).

PIC, He, I, Ne and Rp were obtained to measure the ability of 28 iPBS markers in the present study. The maximum PIC value was 0.87 for iPBS 2245, and the lowest was 0.18 for iPBS 2273 (Table 3). The average number of PIC for all primers was calculated as 0.66 , and this result being close to 1 indicated that the primers used in this study were considerably informative. The mean value of Shannon's information index (I) was found to be 1.29 and ranged from 0.18 (iPBS 2273) to 2.91 (iPBS 2401) (Table 3). On the other hand, the average number of Ne was 0.69 (Table 3). The quantity of gene diversity (He) was observed in iPBS 2224 with a maximum value of 0.40 and in iPBS 2085 and 2392 with a minimum value of 0.08 . The average amount of gene diversity $(\mathrm{He})$ was 0.25 for 235 individuals in the entire study, showing a high level of variation (Table 3 ).

\section{Cluster and principal component analyses}

Using the iPBS data and the similarity coefficient method of Jaccard, a genetic distance matrix of $B D$ genotypes was determined in the $\mathrm{R}$ studio software. The genetic distance matrix results can be found at the website of

https://www.dropbox.com/s/omtrp72qllevd9y/genetic\%20 distance $\% 20$ matrix.xlsx?dl=0. The genetic distance level analyses indicated that all values varied from 0.04 to 0.67 , indicating a high level of variation. In addition, the closest genotypes in the population were Geno65 (Sehitlik, Canakkale) and Geno68 (Sehitlik, Canakkale), while the most distant genotypes were Geno58 (Kozluk, Batman) and Geno115 (Tavsanli, Kutahya).

The UPGMA dendrogram with a heat map showed that the population mainly consisted of two groups, and as shown in Figure 2, while group 1 mainly comprised 161 genotypes collected from coastal regions of Turkey, group 2 mainly included 74 genotypes collected from inland Turkey (Figure 2; cluster 1 in red and cluster 2 in green). In addition, these groups were split into various subgroups. Supporting the results of UPGMA and heat map, PCoA diagram also demonstrated that the population split into two groups (Figure 3; cluster 1 in red and cluster 2 in green). These results present a clear and sharp variation between the $235 B D$ genotypes.

\section{Population structure analyses}

A total of 184 polymorphic bands produced by 28 iPBS primers (Table 2) were used for genotyping. The population structure of $235 \mathrm{BD}$ genotypes was identified using STRUCTURE HARVESTER (v.2.2) (Earl and VonHoldt, 2012) based on the most appropriate group number estimation (Delta K). The highest value of Delta $\mathrm{K}$ was indicated $\mathrm{K}=2$ on the graph (Figure 5). At this level ( $\mathrm{K}=$ 2) of discrimination, the genotypes were split into two main groups (Figure 4; cluster 1 in red and cluster 2 in green).

The expected heterozygosity, which helps to examine the probability of separation between two randomly chosen genotypes, was measured as 0.14 for the first group and 0.15 for the second group at $\mathrm{K}=2$. Additionally, the average Fst values were computed as 0.43 for the first group and 0.33 for the second group with an average of 0.38 , at $\mathrm{K}=2$. This high expected heterozygosity and Fst values display the presence of a great heterozygosity among the $B D$ genotypes. 
Table 2. List of iPBS primers used in the current study

\begin{tabular}{cccc}
\hline Primer ID & Optimal Annealing Temperature $\left({ }^{\circ} \mathbf{C}\right)$ & Nucleotide Number & Sequence \\
\hline iPBS 2085 & 55 & 12 & ATGCCGATACCA \\
iPBS 2087 & 48 & 12 & GCAATGGAACCA \\
iPBS 2389 & 48 & 12 & ACATCCTTCCCA \\
iPBS 2391 & 45 & 12 & ATCTGTCAGCCA \\
iPBS 2392 & 48 & 12 & TAGATGGTGCCA \\
iPBS 2393 & 45 & 12 & TACGGTACGCCA \\
iPBS 2273 & 45 & 13 & GCTCATCATGCCA \\
iPBS 2217 & 48 & 18 & ACTTGGATGTCGATACCA \\
iPBS 2221 & 51 & 18 & ACCTAGCTCACGATGCCA \\
iPBS 2222 & 46 & 18 & ACTTGGATGCCGATACCA \\
iPBS 2224 & 51 & 18 & ATCCTGGCAATGGAACCA \\
iPBS 2228 & 51 & 18 & CATTGGCTCTTGATACCA \\
iPBS 2229 & 48 & 18 & CGACCTGTTCTGATACCA \\
iPBS 2230 & 45 & 18 & TCTAGGCGTCTGATACCA \\
iPBS 2241 & 51 & 18 & ACCTAGCTCATCATGCCA \\
iPBS 2243 & 51 & 18 & AGTCAGGCTCTGTTACCA \\
iPBS 2245 & 51 & 18 & GAGGTGGCTCTTATACCA \\
iPBS 2251 & 54 & 18 & GAACAGGCGATGATACCA \\
iPBS 2252 & 45 & 18 & TCATGGCTCATGATACCA \\
iPBS 2255 & 45 & 18 & GCGTGTGCTCTCATACCA \\
iPBS 2257 & 48 & 18 & CTCTCAATGAAAGCACCA \\
iPBS 2295 & 51 & 18 & AGAACGGCTCTGATACCA \\
iPBS 2298 & 45 & 18 & AGAAGAGCTCTGATACCA \\
iPBS 2373 & 51 & 18 & GAACTTGCTCCGATGCCA \\
iPBS 2399 & 45 & 18 & AAACTGGCAACGGCGCCA \\
iPBS 2400 & 51 & 18 & CCCCTCCTTCTAGCGCCA \\
iPBS 2401 & 53 & 18 & AGTTAAGCTTTGATACCA \\
iPBS 2402 & 51 & 18 & TCTAAGCTCTTGATACCA \\
\hline
\end{tabular}

Table 3. Information of the iPBS primers used in the current study

\begin{tabular}{|c|c|c|c|c|c|c|c|c|}
\hline Primer ID & TB & PB & PR (\%) & PIC & $\mathrm{Ne}$ & I & $\mathbf{H e}$ & $\mathbf{R p}$ \\
\hline iPBS 2085 & 8 & 8 & 100 & 0.75 & 0.10 & 0.77 & 0.08 & 0.75 \\
\hline iPBS 2087 & 9 & 7 & 78 & 0.78 & 0.65 & 1.49 & 0.24 & 2.41 \\
\hline iPBS 2217 & 5 & 4 & 80 & 0.76 & 1.05 & 0.61 & 0.12 & 0.52 \\
\hline iPBS 2221 & 10 & 9 & 90 & 0.59 & 0.27 & 1.49 & 0.20 & 2.46 \\
\hline iPBS 2222 & 7 & 5 & 71 & 0.72 & 0.71 & 0.68 & 0.15 & 0.97 \\
\hline iPBS 2224 & 7 & 5 & 71 & 0.76 & 0.85 & 1.56 & 0.40 & 3.13 \\
\hline iPBS 2228 & 13 & 12 & 92 & 0.68 & 0.26 & 2.54 & 0.26 & 4.63 \\
\hline iPBS 2229 & 10 & 9 & 90 & 0.60 & 0.28 & 2.07 & 0.31 & 4.47 \\
\hline iPBS 2230 & 5 & 3 & 60 & 0.85 & 2.26 & 0.75 & 0.49 & 1.50 \\
\hline iPBS 2241 & 9 & 8 & 89 & 0.68 & 0.34 & 2.04 & 0.35 & 4.42 \\
\hline iPBS 2243 & 11 & 8 & 73 & 0.71 & 0.43 & 1.33 & 0.19 & 2.50 \\
\hline iPBS 2245 & 8 & 6 & 75 & 0.87 & 1.33 & 1.59 & 0.30 & 2.67 \\
\hline iPBS 2251 & 5 & 4 & 80 & 0.47 & 0.47 & 0.79 & 0.28 & 1.56 \\
\hline iPBS 2252 & 5 & 4 & 80 & 0.74 & 0.95 & 0.97 & 0.30 & 1.67 \\
\hline iPBS 2255 & 11 & 11 & 100 & 0.73 & 0.34 & 2.46 & 0.28 & 4.40 \\
\hline iPBS 2257 & 4 & 4 & 100 & 0.21 & 0.32 & 0.42 & 0.19 & 0.95 \\
\hline iPBS 2273 & 2 & 2 & 100 & 0.18 & 0.61 & 0.18 & 0.17 & 0.37 \\
\hline iPBS 2295 & 10 & 9 & 90 & 0.82 & 0.61 & 0.75 & 0.20 & 2.45 \\
\hline iPBS 2298 & 12 & 12 & 100 & 0.86 & 0.58 & 2.65 & 0.23 & 3.70 \\
\hline iPBS 2373 & 10 & 8 & 80 & 0.61 & 0.32 & 1.99 & 0.35 & 4.52 \\
\hline iPBS 2389 & 7 & 7 & 100 & 0.60 & 0.36 & 1.14 & 0.21 & 1.95 \\
\hline iPBS 2391 & 7 & 5 & 71 & 0.77 & 0.88 & 0.69 & 0.17 & 1.21 \\
\hline iPBS 2392 & 6 & 5 & 83 & 0.46 & 0.37 & 0.32 & 0.08 & 0.42 \\
\hline iPBS 2393 & 4 & 4 & 100 & 0.54 & 0.55 & 0.98 & 0.37 & 2.14 \\
\hline iPBS 2399 & 6 & 6 & 100 & 0.50 & 0.35 & 0.87 & 0.20 & 1.71 \\
\hline iPBS 2400 & 5 & 4 & 80 & 0.76 & 1.02 & 0.55 & 0.12 & 0.14 \\
\hline iPBS 2401 & 13 & 13 & 100 & 0.74 & 0.29 & 2.91 & 0.25 & 4.64 \\
\hline iPBS 2402 & 3 & 2 & 67 & 0.82 & 2.72 & 0.61 & 0.38 & 1.15 \\
\hline Average & 7.57 & 6.57 & 86 & 0.66 & 0.69 & 1.29 & 0.25 & 2.27 \\
\hline Total & 212 & 184 & \multicolumn{6}{|c|}{$\begin{array}{l}\text { TB: Total bands number, PB: Polymorphic bands number, PR: Polymorphism rate, } \\
\text { PIC: Polymorphism information contents, Ne: Effective allele number, I: } \\
\text { Shannon's information index, He: Nei's gene diversity, Rp: Resolving power. }\end{array}$} \\
\hline
\end{tabular}




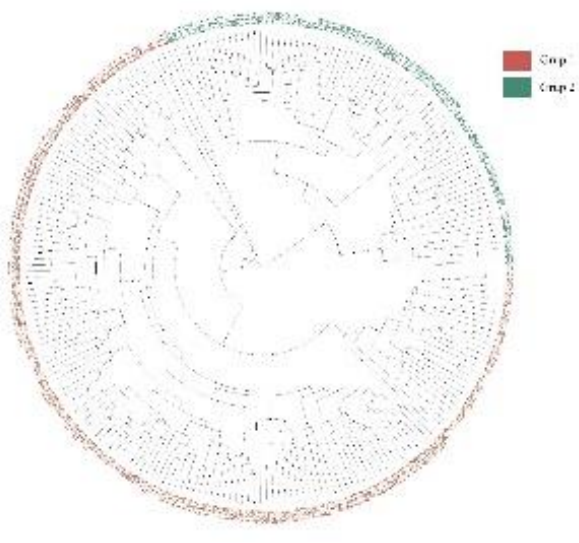

Figure 2. UPGMA dendrogram of 235 B. distachyon genotypes

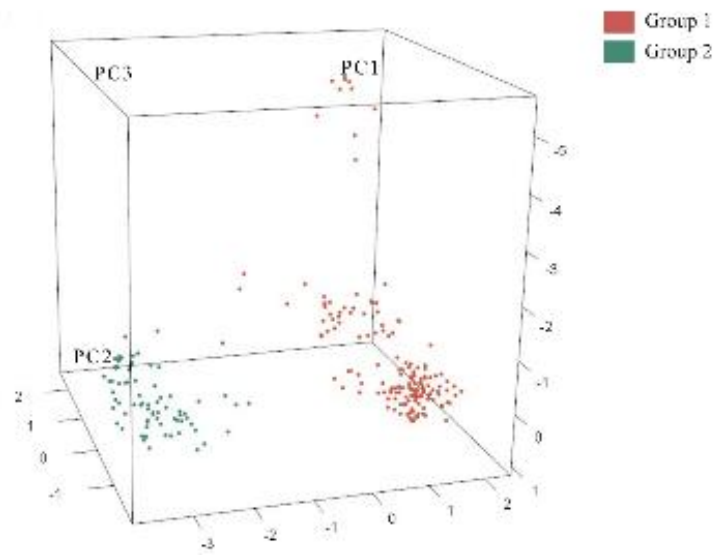

Figure 3. Principal coordinate analysis (PCoA) plot for $235 \mathrm{~B}$. distachyon genotypes based on iPBS data
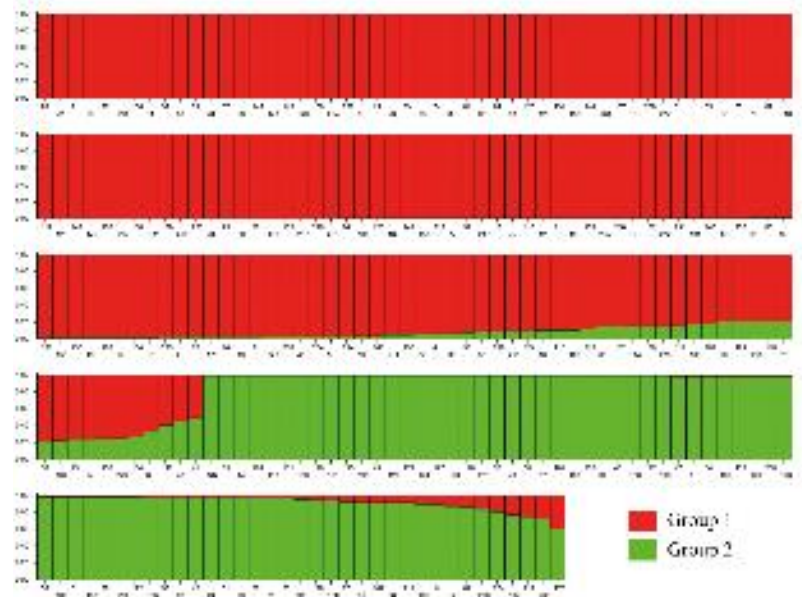

Figure 4. Population structure of 235 B. distachyon accessions genotypes used in the study $(\mathrm{K}=2)$

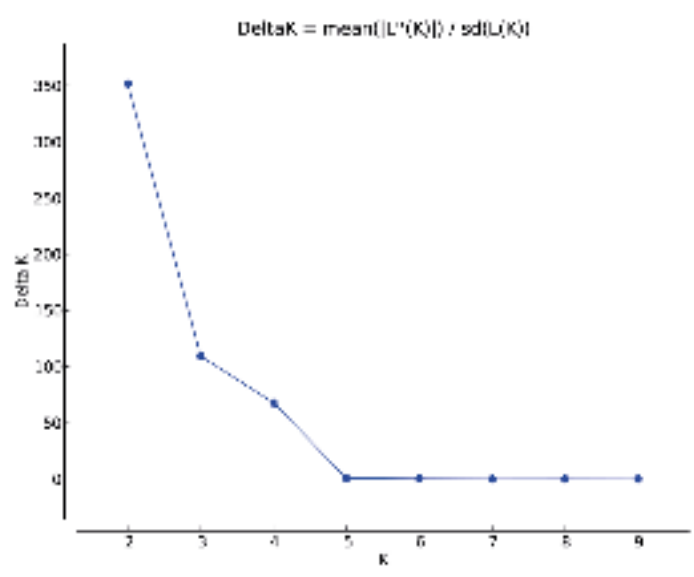

Figure 5. The Delta K of 10 repeats based on the STRUCTURE analyses

\section{Relative kinship}

In the current study, 184 polymorphic loci were used to indicate the relative kinship in the BD genotypes, and the pairwise kinship values were between 0 and 1 . The calculations indicated that more than $82.3 \%$ of the pairwise kinship estimates ranged from 0 to 0.2 kinship values (Figure 6). In addition, 97.2\% of the relative kinship estimates were less than 0.4 (Figure 6), meaning that while a great majority of the genotypes were a distant relative, some presented high similarity.

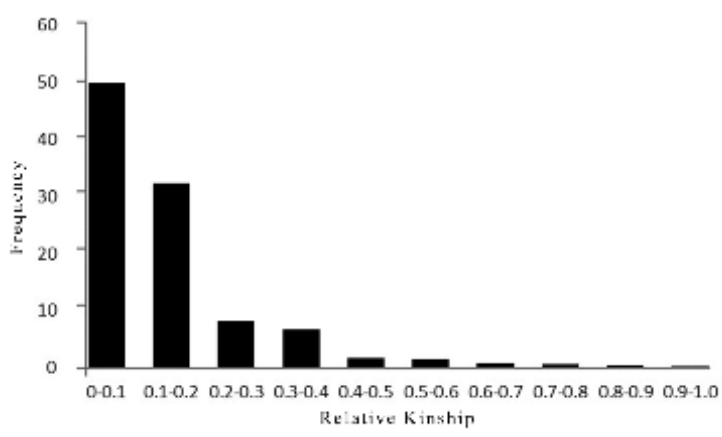

Figure 6. The distribution of pairwise relative kinship values

\section{DISCUSSION}

Analyses of genetic diversity and relationships between genotypes are important for their effective utilisation in crop improvement studies. Genetic diversity analyses provide an understanding of the genetic variation level and population structure (Ellegren and Galtier, 2016). BD has the smallest genome in the Poaceae and is phylogenetically close to wheat, rice and sorghum; therefore, it acts as a powerful functional genomics resource for all grasses (Draper et al., 2001; Vogel et al., 2010). 
Analyses of iPBS markers and genetic diversity in B. distachyon

The results of band polymorphisms per primer were greater than reported as 3.8 in the common bean (Nemli et al., 2015), and 2.7 in fig (Belttar et al., 2017). These results indicate that $\mathrm{PBS}$ primers were more conserved for $B D$ compared to these species used in previous studies (Nemli et al., 2015; Belttar et al., 2017). On the other hand, a few iPBS studies have reported polymorphic alleles amplified per primer more than in the current study; for instance, apricot (Baránek et al., 2012), pea (Baloch et al., 2015), grape (Guo et al., 2014), rice (Comertpay et al., 2016), chickpea (Andeden et al., 2013) and saffron (Gedik et al., 2017 ) detected the number of polymorphic bands as 6.6 , $6.7,7.1,8.5,13$ and 25.1 , respectively. This is because the $B D$ genome is very small and the amount of retrotransposons is variable among different species (Draper et al., 2001; Kalendar et al., 2019). Additionally, the average polymorphism found in this study was greater than previous studies in B. distachyon, such as AFLP (\%70) (Filiz et al., 2009), SSR (\%66) (Vogel et al., 2009), SSR, and inter simple sequence repeat (ISSR) (26\% and $16 \%$, respectively) (Hammami et al., 2014).

The PIC value indicates a stronger prediction of genetic diversity than the number of bands, since it calculates the comparative frequencies of each band (Comertpay et al., 2016). In the present study, the calculated mean PIC value was 0.66 per primer (Table 3). In previous iPBS studies, the mean PIC values were detected as 0.61 in pea (Baloch et al., 2015), 0.35 in rice (Comertpay et al., 2016), and 0.17 in cotton (Tyagi et al., 2014). Our average PIC value (0.66) was greater than these studies. On the other hand, the RP value is closely associated with a primer's ability to distinguish the genotypes, and the RP values ranged from 0.14 (iPBS 2400) to 4.64 (iPBS 2401) with an average of 2.27 in this study (Table 3 ). In previous iPBS studies, the RP values ranged from 1.43 (iPBS 2231) to 5.60 (iPBS 2230) in grape (Guo et al., 2014) and from 4.32 (iPBS 2377) to 11.20 (iPBS 2230) in Tetradium ruticarpum (Xu et al., 2018). The result of the RP analysis indicates that the type of germplasm being examined affects the resolving power of the primers (Sarla et al., 2003). These PIC and RP results not only demonstrated that all primers studied in this research were sufficiently powerful to establish the polymorphism but also the iPBS markers were notably useful in identifying genetic diversity in B. distachyon.

The mean values of Shannon's information index (I) and Nei's genetic diversity $(\mathrm{H})$ among $B D$ genotypes were calculated as 1.29 and 0.25 , respectively (Table 3 ). For these calculations, higher values indicate high genetic diversity, and for this reason, there was a great variation between the BD genotypes. The mean Shannon's information index (I) (1.29) and Nei's genetic diversity $(\mathrm{H})$ $(0.25)$ in this study was greater than previous studies, such as in rice as 0.30 and 0.23 (Comertpay et al., 2016) and in saffron as 0.29 and 0.16 (Gedik et al., 2017). In addition, in this study, the number of effective alleles belonging to the locus of lines (Ne) ranged from 0.10 (iPBS 2085) to 2.72 (iPBS 2402) with an average of 0.69 (Table 3).

\section{Analyses of population structure}

The genetic diversity analysis between $235 B D$ genotypes using 28 iPBS primers was clearly illustrated in the UPGMA dendrogram (Figure 2) based on the pairwise genetic distance coefficient scores. The genetic distance values ranged between 0.04 and 0.67 , and the closest genotypes were Geno66 (Sehitlik, Canakkale) and Geno67 (Sehitlik, Canakkale), while the maximum genetic variation was identified between Geno58 (Kozluk, Batman) and Geno115 (Tavsanli, Kutahya). In line with this result, genetically distant genotypes (Geno58 and Geno115) could be chosen as candidate parents to observe great segregation in $\mathrm{F}_{2}$. On the other hand, in the results of the dendrogram (Figure 2; cluster 1 in red and cluster 2 in green) and PCoA (Figure 3; cluster 1 in red and cluster 2 in green), the population was made up of two groups with great diversity. In an earlier study of Turkish $B D$ using AFLP, a UPGMA dendrogram divided the population into five groups according to their geographic origins (Filiz et al., 2009). The reason for this can be considered as the use of different genotypes and DNA being divided into very small meaningless parts with DNA restriction enzymes in the AFLP method.

The analysis of the population structure indicated that the genotypes were clustered into two groups (Figure 4; cluster 1 in red and cluster 2 in green). Group 1 consisted of genotypes collected mainly from coastal cities, while group 2 comprised genotypes collected from inland Turkey (Figure 1; cluster 1 in red and cluster 2 in green). Thus, this result demonstrated that the distribution of Turkish $B D$ genotypes used in the current study depended on the locations (coastal regions or inland Turkey) with a few exceptions. This clustering result also supports a previous study on Turkish BD using SSR markers (Vogel et al., 2009). In that SSR study, inland lines generated one of the two groups, while the line forming the other group was collected from a coastal city (Vogel et al., 2009). These findings agree with the results of population structure analyses of $B D$ using the DNA barcoding method (LópezAlvarez et al., 2012), SNP (Tyler et al., 2016) and SSR (Vogel et al., 2009). In another previous population structure analysis of $B D$ using SSR, similar to our results, the genotypes were split into two main clusters based on the geographic regions and one of the clusters was made of Californian genotypes, while the other cluster comprised of mainly Eurasian genotypes (Bakker et al., 2009). Furthermore, in the current study some genotypes belonging to close locations were found to have high genetic distance, showing that there is a low gene flow among genotypes, consistent with high self-fertilization rates in $B D$ (Tyler et al., 2016).

The Fst inbreeding coefficient presents a measure of the genetic heterozygosity between subpopulations (Ochoa and Storey, 2019). The calculation of Fst using the structure analysis of the current study was 0.43 for the first group and 0.33 for the second group, and these results indicated a 
great differentiation within subgroups. Moreover, group 1 had ahigher $F$ st value than group 2 as expected since the genotypes collected from the coastal regions of Turkey had a wide range of geographic location. In the previous AFLP study of Turkish B. distachyon, for all pairwise comparisons between different locations, the $F$ st values were considerably different from zero; thus, there was a large variation between populations (Filiz et al., 2009). A considerable amount of natural diversity was also observed in the wild grass $B D$ according to a phenotypic characterisation study (Tyler et al., 2014). In previous studies, the $F s t$ values were detected as 0.36 in barley (Forsberg et al., 2019), 0.18 in durum wheat (Maccaferri et al., 2005) and 0.85 in rice (Garris et al., 2003). The differences in the genetic variation levels between these close grain species may be due to differences in their breeding history and cultivation rates in the habitats of the genotypes (Casler, 2012). Furthermore, the expected heterozygosity values $(0.15$ for group 1 and 0.14 for group 2) demonstrated that $B D$ genotypes in Turkey had a great level of genetic variation, supporting the $F$ st value.

\section{CONCLUSION}

It was demonstrated that $235 \mathrm{~B}$. distachyon genotypes collected from coastal and inland regions of Turkey had large genetic variation. The iPBS marker system differentiated successfully the population collected from Turkey. This marker system presented a high level of genome diversity among the $B D$ genotypes despite its small genome size. A clear distinction was found between the $B D$ genotypes collected from the coastal and inland areas of Turkey. The major reason for broad genetic differences between coastal and inner land regions might be resulted from changes in the $\mathrm{TE}$ regions due to adaptation for different climatic conditions.

The data obtained from $B$. distachyon population will be helpful for the researchers of the Poaceae family.

\section{ACKNOWLEDGEMENTS}

We are grateful to Ege University, Faculty of Agriculture for permission to use their greenhouses.

\section{LITERATURE CITED}

Ali, F., A. Yılmaz, M.A. Nadeem, E. Habyarimana, I. Subasi, M.A. Nawaz, H.J. Chaudhary, M.Q. Shahid, S. Ercisli, M.A.B. Zia, G. Chung and F.S. Baloch. 2019. Mobile genomic element diversity in world collection of safflower (Carthamus tinctorius L.) panel using iPBS-retrotransposon markers. PLoS One. 14:e0211985.

Andeden, E.E., F.S. Baloch, M. Derya, B. Kilian and H. Ozkan. 2013. iPBS-Retrotransposons-based genetic diversity and relationship among wild annual Cicer species. Journal of Plant Biochemistry and Biotechnology. 22:453-466.

Anderson, J.A., G. Churchill, J. Autrique, S. Tanksley and M. Sorrells. 1993. Optimizing parental selection for genetic linkage maps. Genome. 36:181-186.

Bakker, E.G., B. Montgomery, T. Nguyen, K. Eide, J. Chang, T.C. Mockler, A. Liston, E.W. Seabloom and E.T. Borer. 2009. Strong population structure characterizes weediness gene evolution in the invasive grass species Brachypodium distachyon. Molecular Ecology. 18:2588-2601.
Baloch, F.S., A. Alsaleh, L.E.S. de Miera, R. Hatipoglu, V. Çiftçi, T. Karakoy, M. Yildiz and H.Ozkan. 2015. DNA based iPBSretrotransposon markers for investigating the population structure of pea (Pisum sativum) germplasm from Turkey. Biochemical Systematics and Ecology. 61:244-252.

Baránek, M., M. Meszáros, J. Sochorová, J. Čechová and J. Raddová. 2012. Utility of retrotransposon-derived marker systems for differentiation of presumed clones of the apricot cultivar Velkopavlovická. Scientia Horticulturae. 143:1-6.

Belttar, H., A. Yahia, S. Nemli, D. Ates, S. Erdogmus, B. Ertan, S. Himour, S. Hepaksoy and M.B. Tanyolac. 2017. Determination of the population structure of fig genotypes from Algeria and Turkey using inter primer binding siteretrotransposon and simple sequence repeat markers. Agricultural Sciences. 8:1337-1357.

Bevan, M.W., D.F. Garvin and J.P. Vogel. 2010. Brachypodium distachyon genomics for sustainable food and fuel production. Current Opinion in Biotechnology. 21(2):211-217.

Casler, M.D. 2012. Switchgrass breeding, genetics, and genomics. Green Energy and Technology. 29-53.

Comertpay, G., F.S. Baloch, M. Derya, E.E. Andeden, A. Alsaleh, H. Surek and H. Ozkan. 2016. Population structure of rice varieties used in Turkish rice breeding programs determined using simple-sequence repeat and inter-primer binding siteretrotransposon data. Genetics and Molecular Research. 15:1.

Doyle, J.J. and J.L. Doyle. 1987. A rapid DNA isolation procedure for small quantities of fresh leaf tissue. Phytochemical Bulletin. 19:11-15.

Draper, J., L.A.J. Mur, G. Jenkins, G.C. Ghosh-Biswas, P. Bablak, R. Hasterok and A.P.M. Routledge. 2001. Brachypodium distachyon. A new model system for functional genomics in grasses. Plant Physiology. 127:1539-1555.

Earl, D.A. and B.M.VonHoldt. 2012. STRUCTURE HARVESTER: A website and program for visualizing STRUCTURE output and implementing the Evanno method. Conservation Genetics Resources. 4:359-361.

Ellegren, H. and N. Galtier. 2016. Determinants of genetic diversity. Nature Reviews Genetics. 17:422-433.

Evanno, G., S. Regnaut and J. Goudet. 2005. Detecting the number of clusters of individuals using the software STRUCTURE: A simulation study. Molecular Ecology. 14:2611-2620.

Filiz, E., B.S. Ozdemir, F. Budak, J.P. Vogel, M. Tuna and H. Budak. 2009. Molecular, morphological, and cytological analysis of diverse Brachypodium distachyon inbred lines. Genome. 52:876-890.

Forsberg, N.E.G., M.W. Leino and J. Hagenblad. 2019. Population structure in landrace barley (Hordeum vulgare L.) during the late 19th century crop failures in Fennoscandia. Heredity. 123:733-745.

Garris, A.J., S.R. McCouch and S. Kresovich. 2003. Population structure and its effect on haplotype diversity and linkage disequilibrium surrounding the xa5 locus of rice (Oryza sativa L.). Genetics. 165:759-769.

Gedik, A., D. Ates, S. Erdogmus, G. Comertpay, M.B. Tanyolac and H. Ozkan. 2017. Genetic diversity of Crocus sativus and its close relative species analyzed by iPBS-retrotransposons. Turkish Journal of Field Crops. 22:2

Gordon, S.P., H. Priest, D.L. Des Marais, W. Schackwitz, M. Figueroa, J. Martin, J.N. Bragg, L. Tyler, C.R. Lee, D. Bryant, W. Wang, J. Messing, A.J. Manzaneda, K. Barry, D.F. Garvin, H. Budak, M. Tuna, T. Mitchell-Olds, W.F. Pfender, T.E. Juenger, T.C. Mockler and J.P. Vogel. 2014. Genome diversity in Brachypodium distachyon: Deep sequencing of highly diverse inbred lines. Plant Journal. 79:361-374. 
Guo, D.L., M.X. Guo, X.G. Hou and G.H. Zhang. 2014. Molecular diversity analysis of grape varieties based on iPBS markers. Biochemical Systematics and Ecology. 52:27-32.

Hammami, R., N. Jouve, C. Soler, E. Frieiro and J.M. González. 2014. Genetic diversity of SSR and ISSR markers in wild populations of Brachypodium distachyon and its close relatives B. stacei and B. hybridum (Poaceae). Plant Systematics and Evolution. 300:2029-2040.

Kalendar, R., A. Amenov and A. Daniyarov. 2019. Use of retrotransposon-derived genetic markers to analyse genomic variability in plants. Functional Plant Biology. 46(1):15-29.

Kalendar, R., K. Antonius, P. Smýkal and A.H. Schulman. 2010. iPBS: A universal method for DNA fingerprinting and retrotransposon isolation. Theoretical and Applied Genetics. 121:1419-1430.

Kalendar, R., A.J. Flavell, T.H.N. Ellis, T. Sjakste, C. Moisy and A.H. Schulman. 2011. Analysis of plant diversity with retrotransposon-based molecular markers. Heredity. 106:520530.

López-Alvarez, D., M.L. López-Herranz, A. Betekhtin and P. Catalán. 2012. A DNA barcoding method to discriminate between the model plant Brachypodium distachyon and its close relatives B. stacei and B. hybridum (Poaceae). PLoS ONE. 7:e51058.

Maccaferri, M., M.C. Sanguineti, E. Noli and R. Tuberosa. 2005. Population structure and long-range linkage disequilibrium in a durum wheat elite collection. Molecular Breeding. 15:271290.

Nemli, S., T. Kianoosh and M.B. Tanyolac. 2015. Genetic diversity and population structure of common bean (Phaseolus vulgaris L.) accessions through retrotransposonbased interprimer binding sites (iPBSs) markers. Turkish Journal of Agriculture and Forestry. 39:940-948.

Ochoa, A. and J.D. Storey. 2019. FST and kinship for arbitrary population structures I: Generalized definitions. BioRxiv. https://doi.org/10.1101/083915.

Ozdemir, B.S., P. Hernandez, E. Filiz and H. Budak. 2008. Brachypodium genomics. International Journal of Plant Genomics. 2008:536104.

Pal, N.R., J.C. Bezdek and R.J. Hathaway. 1996. Sequential competitive learning and the fuzzy c-means clustering algorithms. Neural Networks. 9(5):787-796.

Pereira, J.F and P.R. Ryan. 2019. The role of transposable elements in the evolution of aluminium resistance in plants. Journal of Experimental Botany. 70(1):41-54.

Prevost, A. and M.J.Wilkinson. 1999. A new system of comparing PCR primers applied to ISSR fingerprinting of potato cultivars. Theoretical and Applied Genetics. 98:107-112.

Pritchard, J.K., M. Stephens and P. Donnelly. 2000. Inference of population structure using multilocus genotype data. Genetics. 155:945-959.
Roy, N.S., J.Y. Choi, S Il. Lee and N.S. Kim. 2014. Marker utility of transposable elements for plant genetics, breeding, and ecology: a review. Genes and Genomics. 37:141-147.

Sarla, N., S. Bobba and E.A. Siddiq. 2003. ISSR and SSR markers based on AG and GA repeats delineate geographically diverse Oryza nivara accessions and reveal rare alleles. Current Science. 84:683-690.

Serrato-Capuchina, A. and D.R. Matute. 2018. The role of transposable elements in speciation.

Shannon, C.E. 1997. The mathematical theory of communication. MD Computing. https://doi.org/10.2307/410457.

Stritt, C., S.P. Gordon, T. Wicker, J.P. Vogel and A.C. Roulin. 2018. Recent activity in expanding populations and purifying selection have shaped transposable element landscapes across natural accessions of the mediterranean grass Brachypodium distachyon. Genome Biology and Evolution. 10:304-318.

Tyagi, P., M.A. Gore, D.T. Bowman, B.T. Campbell, J.A. Udall and V. Kuraparthy. 2014. Genetic diversity and population structure in the US Upland cotton (Gossypium hirsutum L.). Theoretical and Applied Genetics. 127:283-295.

Tyler, L., J.U. Fangel, A.D. Fagerstrom, M.A. Steinwand, T.K. Raab, W.G.T. Willats and J.P. Vogel. 2014. Selection and phenotypic characterization of a core collection of Brachypodium distachyon inbred lines. BMC Plant Biology. $14: 25$.

Tyler, L., S.J. Lee, N.D. Young, G.A. Deiulio, E. Benavente, M. Reagon, J. Sysopha, R.M. Baldini, A. Troìa, S.P. Hazen and A.L. Caicedo. 2016. Population structure in the model grass Brachypodium distachyon is highly correlated with flowering differences across broad geographic areas. Plant Genome. 9:2.

Vogel, J., D. Garvin, T.C. Mockler, J. Schmutz, D. Rokhsar and M. Bevan. 2010. Genome sequencing and analysis of the model grass Brachypodium distachyon. Nature. 463:763-768.

Vogel, J.P., M. Tuna, H. Budak, N. Huo, Y. Q. Gu and M.A. Steinwand. 2009. Development of SSR markers and analysis of diversity in Turkish populations of Brachypodium distachyon. BMC Plant Biology. 9:88.

Wilson, P.B., J.C. Streich, K.D. Murray, S.R. Eichten, R. Cheng, N.C. Aitken, K. Spokas, N. Warthmann, S.P. Gordon, J.P. Vogel, J.O. Borevitz, S. Liu, K. Bradford, S. Ezrati, H. Budak, D. Lopez, P. Catalan, D. Garvin, J. Vogel, S. Gordon, S. Hazen and L. Mur. 2019. Global diversity of the Brachypodium species complex as a resource for genomewide association studies demonstrated for agronomic traits in response to climate. Genetics. 211:317-331.

Xu, J.Y., Y. Zhu, Z. Yi, G. Wu, G.Y. Xie and M.J. Qin. 2018. Molecular diversity analysis of Tetradium ruticarpum (WuZhuYu) in China based on inter-primer binding site (iPBS) markers and inter-simple sequence repeat (ISSR) markers. Chinese Journal of Natural Medicines. 16:1-9. 